\title{
Incentive preference under two levels of water deprivation in the rat
}

\author{
JEROME S. COHEN and ANKE OÖSTENDORP \\ University of Windsor, Windsor, Ontario, Canada N9B $3 P 4$
}

\begin{abstract}
Rats under high $(23.5 \mathrm{~h})$ or moderate $(18 \mathrm{~h})$ water deprivation were required to learn a simultaneous goal door discrimination with $\mathrm{S}+$ position correlated with incentive (water and $20 \%$ sucrose). A series of free choice trials with $S+$ simultaneously present at both incentive positions followed the initial discrimination. Moderately deprived animals made more errors and ran more slowly to $\mathrm{S}+$ when it occurred on the water side than when on the sucrose side during discrimination trials. Highly water-deprived animals displayed less consistent and less differentiated speeds between incentives. Both deprivation groups preferred sucrose to water on free choice tests, but only moderately deprived animals tended to exclusively choose sucrose. The results were interpreted as indicating that the two deprivation levels substantially created different thirst arousal conditions in the animals.
\end{abstract}

A major concern in the investigation of the effects of deprivation on cue utilization in complex discriminations is the level of lower deprivation schedules. Such conditions must provide enough motivation to support discrimination learning and also produce differential hunger or thirst conditions between the deprivation levels. Several experiments from our laboratory have contrasted redundant-relevant or incidental cue discrimination between rats maintained on moderate water deprivation of $18 \mathrm{~h} /$ day and rats maintained on high deprivation of $23.5 \mathrm{~h} /$ day (Cohen, Stettner, \& Michael, 1969; Cohen \& Sullivan, 1973; Cohen \& Telegdy, 1970; Cohen \& Tubaro, 1974; Telegdy \& Cohen, 1971). The moderate water-deprivation condition was determined from earlier pilot research which demonstrated that animals under lower deprivation were too erratic in acquiring the initial discrimination. Our last two studies, however, failed to replicate earlier findings that decreased deprivation led to increased cue utilization. Therefore, thie question remains as to whether the two deprivation levels produce different levels of thirst arousal in rats. In order to answer this question, an experiment was performed to determine if moderately water-deprived animals differed from highly deprived animals in sucrose incentive preferences. This strategy for investigating water-deprivation differences seemed useful to employ, since a substantive body of research has shown marked incentive preference differences between highly water-deprived and water-satiated or food-deprived animals.

When incentives are simultaneously presented (free choice), food-deprived or nondeprived animals invariably prefer high sucrose concentrations over lower concentrations or water. Water-deprived animals either

The present study is based on a paper delivered at the Canadian Psychological Association convention, Quebec City, Quebec, June 1975. The authors are indebted to R. C. Beck, Wake Forest University, Winston-Salem, North Carolina, for his valuable criticism of the manuscript. show no preferences (Beck \& Bidwell, 1974; Beck \& Nash, 1969; Beck, Nash, Viernstein, \& Gordon, 1972; Beck, Self, \& Carter, 1965) or prefer water to sucrose (Cohen \& Tokieda, 1972). These incentive preferences, or lack of them, in highly deprived animals are not invariant since, in three of the above studies (Beck et al., 1972; Beck \& Nash, 1969; Cohen \& Tokieda, 1972), reinforcement access of $1 \mathrm{~min}$ or more/trial or prewatering led to sucrose preference in highly water-deprived animals.

An indirect method of assessing incentive preferences has been to measure strength of instrumental activity to separately presented incentives (forced choice). Under this paradigm, type of deprivation (water, food, or nondeprived) also affects incentive preference. Food- and nondeprived animals respond more (barpress rates) for higher sucrose concentrations, while highly waterdeprived animals either respond at similar rates to all incentives (water-64\% sucrose concentration) (Beck, 1963; Oakley, 1965; Rosen \& Jacobs, 1968; Tombaugh, 1974 ) or develop faster rates to water (Beck \& Ellis, 1966). Again it should be noted that such response differences between deprivation conditions are not invariant. Highly water-deprived animals would also begin to respond more vigorously to sucrose than water at the end of lengthy experimental sessions of $30 \mathrm{~min}$ or more (Rosen \& Jacobs, 1968).

The present experiment was conducted as follows. Animals under high $(23.5 \mathrm{~h} /$ day $)$ and moderate $(18 \mathrm{~h} /$ day $)$ water deprivation were required to learn a simultaneous brightness discrimination with position of S+ correlated with incentive (water and 20\% sucrose). Access to reinforcement on each trial was limited to $10 \mathrm{sec}$. A series of free choice trials followed this initial discrimination training. Incentive preference was indirectly measured by error frequency and running speed to $\mathrm{S}+$ at each incentive position. Direct measure of preference was obtained from the free choice trials. A deprivation counterbalancing procedure was also instituted, 
such that half the animals received their free choice trials under the opposite deprivation condition. The use of a discrimination and deprivation counterbalancing paradigm rendered the present study similar in design to our earlier experiments (Cohen \& Telegdy, 1970; Telegdy \& Cohen, 1971). Thus, results from the present study can be more easily generalized to discrimination tasks in which the effects of water deprivation are to be investigated.

If moderate water-deprivation conditions produce lower thirst motivation than high-deprivation conditions, then the following predictions follow. Moderately water-deprived animals should differ from highly water-deprived animals by displaying more errors and slower running speeds to $\mathrm{S}+$ at the water than at the sucrose location on forced choice trials and greater free choice preferences to sucrose solution. Deprivation counterbalancing allowed us to determine to what extent free choice behavior was influenced by initial and present deprivation levels.

\section{METHOD}

\section{Subjects}

Thirty-two male albino rats (Wistar strain) approximately 90 days of age were used. Sources of animals were the breeding colonies of Woodlyn Farms, Guelph, Ontario, and the Psychology Department, University of Windsor. During the course of the experiment, three animals would not run in the apparatus and were replaced from the same breeding stock.

\section{Apparatus}

A simultaneous two-choice discrimination box consisting of a start chamber, V-shaped decision chamber, and two goal chambers was used. A more detailed description appears elsewhere (Telegdy \& Cohen, 1971). An animal gained entry into a goal chamber by pushing open one of the two goal doors in the decision chamber. A metal drinking tube dispensed reinforcement (water or sucrose solution) in each goal chamber. Running time in the decision chamber was measured to the nearest $.1 \mathrm{sec}$. An animal was placed backward into the start chamber. As soon as it turned around and nosed the clear plastic start chamber door, the experimenter lifted the door, which started an electric stop clock. When the animal opened a goal door, a photoelectric beam was intersected, stopping the clock. The interior of the apparatus was painted matte gray and was illuminated by a 100 -W incandescent bulb located above the start chamber door. Sucrose solutions were made with tap water (weight/volume) and refrigerated. Prior to each experimental session, all liquids were warmed to room temperature.

\section{Procedure}

The procedure consisted of three phases, pretraining, discrimination training, and free choice testing. As the basic procedures were the same as those employed by Telegdy and Cohen (1971), only a brief description of the phases is given.

During pretraining all animals were maintained on a $21 \mathrm{~h} /$ day deprivation schedule $(3 \mathrm{~h} /$ day free access). Food was available ad lib in the animals' home cages. In this phase animals learned to open one of two gray goal doors for 12 spaced experimentercorrected trials/day. Reinforcement was a 10-sec drink of $10 \%$ sucrose solution/trial. In order to acquaint the animals with the basic running procedures in the following phases, one of the goal doors was locked during the last pretraining day. Position of the unlocked door was randomly varied over trials according to Fellows' (1967) sequences. If an animal nosed a locked door, it was immediately replaced in the start chamber and run again until it pushed only the unlocked door. Each animal had to wait until all others had run their trial before proceeding with the next trial. Since eight animals were run at a time, intertrial intervals were 4-6 min.

Following pretraining, animals were randomly divided into two equal groups of high and moderate water deprivation. Rats were given $.5 \mathrm{~h}$ daily free access to water $(23.5 \mathrm{~h} /$ day deprivation) under high deprivation and $6 \mathrm{~h}$ daily free access $(18 \mathrm{~h} /$ day deprivation) under moderate deprivation. Following 3 days of adaptation to their respective deprivation schedules in their home cages, animals were given simultaneous discrimination training. Animals were trained to approach an unlocked black (S+) goal door. The gray door was locked. During this phase, reinforcement was changed to water and $20 \%$ sucrose solutions. Position of S+ was randomly varied over trials according to Fellows' (1967) sequence and was correlated with water and $20 \%$ sucrose liquids. Position of each incentive was held constant throughout the experiment, so that each animal received equal experience ( 6 trials/day) with each incentive. Position of incentives was also counterbalanced within each group according to observed position preferences during pretraining. Animals were trained to a criterion of no more than two errors within two successive sessions ( 24 trials). Five overtraining sessions followed acquisition criterion. Running time/trial to the nearest $.1 \mathrm{sec}$ to $\mathrm{S}+$ at each incentive position was measured during overtraining. These postacquisition sessions were run in order to obtain incentive position speeds uncontaminated by acquisition errors.

Following its final overtraining session, an animal was randomly placed on the other deprivation schedule or maintained on its original deprivation schedule and allowed to adapt to its schedule for 3 days in its home cage. As a result of this counterbalancing procedure, four groups $(n=8)$ were formed and labeled high-high, moderate-moderate, highmoderate, moderate-high. The first label refers to training deprivation and the second to testing deprivation. The free choice test phase, following the 3-day rest, consisted of three sessions (36 trials) in which every third trial was a free choice test. Thus, there were 12 free choice test trials. Both goal doors were black and unlocked on each test trial. An animal could choose either incentive position and, thus, either incentive. Regular forced choice discrimination trials continued to be run on the remaining trials. S+ was presented twice in succession in each position and in both alternations on discrimination trials on each test day (LL, RR, RL, LR) to prevent free choice preferences from being influenced by prior nontest trials. The procedure of interjecting test trials within original discrimination trials was initially used by Sutherland and Holgate (1966) to prevent test trials from becoming specific discrimination trials.

\section{RESULTS}

Error frequency to $\mathrm{S}+$ at each incentive position during acquisition and running speeds to $\mathrm{S}+$ at each incentive position during overtraining are shown in Figures 1 and 2, respectively. Proportion of sucrose solution choices on the free choice trials is shown in Table 1. Mean running speeds were calculated from reciprocal running times to each incentive position on each trial. This transformation was used to normalize typically skewed data, as suggested by Winer (1971).

Deprivation by Incentive Position (repeated measure) for error frequency and Deprivation by Incentive Position by Sessions (repeated measures for last two 


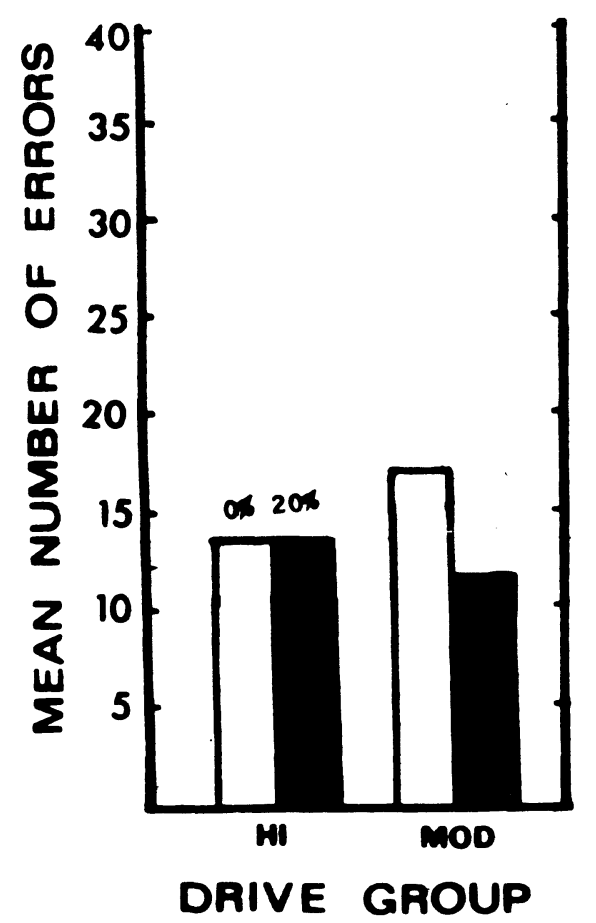

Figure 1. Mean number of errors to criterion to $S+$ at each incentive position (expressed as percent sucrose concentration) for high (HI) and moderate (MOD) water-deprivation (drive) groups.

factors) for running speeds analyses of variance were carried out on the acquisition and overtraining data. Both analyses supported observations from both figures that only moderately deprived animals consistently made more errors and ran more slowly to $\mathrm{S}+$ at the water position than at the sucrose side. Significant effects were found for both measures for Incentive Position $[F(1,30)$ for errors $=4.54, p<.05]$ for running speeds $=85.57$, $\mathrm{p}<.01]$ and for Deprivation by Incentive Position $[F(1,30)$ for errors $=5.50, p<.05$; for running speeds $=$ $19.14, \mathrm{p}<.01]$. A significant Incentive Position by Sessions interaction was found for running speeds $[F(4,120)=5.51, p<.05]$. A series of individual comparisons (Newman-Keuls tests) revealed that only moderately deprived animals made significantly more errors to $\mathrm{S}+$ at the water side than at the sucrose position $(p \leqslant .05)$. Moderately deprived animals ran significantly more slowly to $S+$ at the water position than at the sucrose position over each session $(p \leqslant .01)$. Differences between deprivation groups occurred only to $S+$ at the water position, where moderately deprived animals significantly made more errors $(\mathrm{p} \leqslant .05)$ and ran more slowly $(\mathrm{p} \leqslant .01$ each session) than highly deprived rats. Highly water-deprived animals did appear to run more quickly to $\mathrm{S}+$ at the sucrose than at the water side (see Figure 2). However, such differences were smaller and

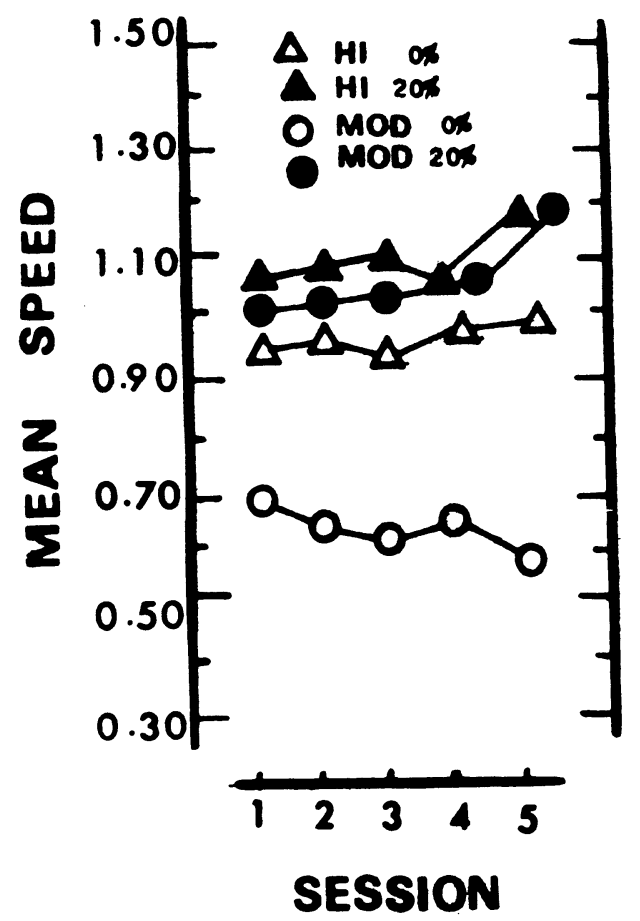

Figure 2. Mean running speeds on overtraining discrimination sessions to $\mathrm{S}+$ at each incentive position (expressed as percent sucrose concentration) for high (HI) and moderate (MOD) waterdeprivation groups.

less consistent than those found for moderately deprived animals. Significant differences between running speeds to each incentive were found only on Overtraining Sessions $2(p \leqslant .05), 3$, and $5(p \leqslant .01)$ in highly deprived animals. Although highly deprived animals took more sessions (mean $=7$ ) to learn the initial discrimination than moderately deprived animals $($ mean $=6)$, this difference was not significant.

As seen in Table 1, all groups, regardless of original or test deprivation, predominantly preferred the sucrose solution on free choice tests. Individual t tests established the significance of these preferences above a random .50 level $(p<.005)$. Although moderately deprived animals appeared to display a greater proportion of sucrose choices, these differences were not significant

Table 1

Proportion (p) of Sucrose Preferences and Number (N) of Animals in Each Group Choosing Sucrose Only on Free Choice Trials

\begin{tabular}{lll}
\hline \multicolumn{1}{c}{ Group } & $\mathrm{p}$ & $\mathrm{N}$ \\
\hline High-High & $.83^{*}$ & 3 \\
High-Moderate & $.79^{*}$ & 4 \\
Moderate-Moderate & $.96^{*}$ & 7 \\
Moderate-High & $.94^{*}$ & 7 \\
\hline
\end{tabular}


according to an analysis of variance. When the number of animals choosing only sucrose were analyzed, however, animals originally trained under moderately deprived conditions showed greater preference than highly deprived animals $\left(\chi^{2}=5.19, \mathrm{df}=1, \mathrm{p}<.05\right)$.

Running speeds were also calculated from the discrimination trials during the last phase. As these measures were similar to those found during the previous phase, only a brief summary is presented. Animals maintained on high deprivation failed to display significant speed differences, while animals maintained on moderate deprivation ran significantly more quickly to sucrose than water $(\mathrm{p} \leqslant .01$ each session). Animals switched from high to moderate deprivation quickly developed faster speeds to sucrose over water from the second session $(\mathrm{p} \leqslant .05)$. Moderately deprived animals switched to high deprivation (moderate-high group) gradually increased their running speed to water and approached their reaction to the sucrose solution by the third session.

\section{DISCUSSION}

Findings from this study strongly indicate that our deprivation procedures produced different thirst motivation levels as measured by incentive preferences. These differences were more clearly found for indirect than for direct measures of incentive preference. Moderately deprived animals made fewer errors and ran more vigorously to $\mathrm{S}+$ at the sucrose than at the water position. Highly deprived animals displayed less consistent and iess dirferentiated running speeds to incentives. When deprivation was shifted to the opposite level, animals changed their running speeds to reflect those of the new deprivation group. Deprivation only marginally affected free choice behavior, however. Initially, highly deprived animals did choose water on some of the free choice trials, while moderately deprived animals almost exclusively preferred sucrose to water. All groups, however, consistently preferred sucrose solutions to water. Deprivation during the initial discrimination appeared to have more effect on free choice behavior when total sucrose preference was measured.

Sucrose preferences in highly deprived animals during free choice trials were unexpected and contrary to findings from previous research. It will be recalled that earlier investigators found that only with considerable prewatering of $5 \mathrm{~min}$ or $14 \mathrm{~g}$ (Cohen \& Tokieda, 1972) or massed trials and incentive access at or beyond 1 min (Beck \& Nash, 1969; Beck et al., 1972) did highly water-deprived animals display sucrose solution preferences. Conditions in our study of spaced trials (4-6 min) and limited access to reinforcement $(10 \mathrm{sec})$ should not have favored sucrose preferences, according to these earlier experiments. Furthermore, the two forced choice trials that preceded every free choice trial could not have provided sufficient amounts of prewatering (only $20 \mathrm{sec}$ ) to increase sucrose preferences, according to results from Cohen and Tokieda (1972).

Two major differences between the present study and earlier research that might account for our free choice results are the level of sucrose concentration used and amount of training given to animals. Lower sucrose concentration (6\%-12\%) and far fewer trials with each incentive were used in earlier work. It should be noted, however, that recently Hachey (Note 1) paired low sucrose concentrations $(5 \%, 10 \%)$ with water in a similar paradigm and still obtained reliably high free choice sucrose preferences in highly water-deprived rats. Other possible factors, such as type and amount of training, that could account for our findings are being investigated in our laboratory.

\section{REFERENCE NOTE}

1. Hachey, G. Development of incentive preference as a function of water deprivation and sucrose concentration. Unpublished Master's Thesis, University of Windsor, 1976.

\section{REFERENCES}

BECK, R. C. Effects of variations in water need and in incentive concentration on bar pressing. Psychological Reports, 1963. 13, 31-37.

BECK, R. C., \& Bidwell, L. D. Incentive motivational properties of sucrose and saccharine under different deprivation conditions. Motivation and Learning, 1974, 5, 328-335.

BECK, R. C., \& Ellis, V. T. Sucrose reinforcement thresinoids for hungry, thirsty, and nondeprived rats. Psychonomic Science, 1966, 4, 199-200.

BeCK, R. C., \& NASH, R. Thirsty rats do prefer sucrose. Psychonomic Science, 1969, 15, 19-20.

Beck, R. C., Nash, R., Viernstein, L., \& Gordon, L. Sucrose preferences of hungry and thirsty rats as a function of duration of stimulus presentation. Journal of Comparative and Physiological Psychology, 1972, 48, 40-50.

Beck, R. C., Self, J. L., \& CARTer, D. J. Sucrose preference thresholds for satiated and water deprived rats. Psychological Reports, 1965, 16, 901-905.

Cohen, J. S., Stettner, L. J., \& Michael, D. J. Effects of deprivation level on span of attention in a multi-dimension discrimination task. Psychonomic Science, 1969, 15, 31-32.

Cohen, J. S., \& Sullivan, B. Effects of drive level on cue utilization of spatially separated redundant relevant cues. Bulletin of the Psychonomic Society, 1973, 1, 455-457.

Cohen, J. S., \& TFlegdy, G. A. Effect of drive level on habit strength in a discrimination task. Psychonomic Science, 1970, 19, 27-29.

Cohen, J. S., \& Tubaro, G. Effects of thirst drive on cue utilization and cue dominance of spatially separate cues in albino rats. Bulletin of the Psychonomic Society, 1974, 4, 451-453.

Cohen, P. S., \& Tokieda, F. K. Sucrose-water preference reversal in the water deprived rat. Journal of Comparative and Physiological Psychology, 1972, 79, 254-258.

Fellows, B. Chance stimulus sequences for discrimination tasks. Psychological Bulletin, 1967, 67, 87-92.

OAKLEY, B. Impaired operant behavior following lesions of the thalamic taste nucleus. Journal of Comparative and Physiological Psychology, 1965, 59, 202-210.

Rosen, A. J., \& Jacobs, M. Sucrose incentive shifts in the Skinner box with thirsty rats. Psychonomic Science, 1968, 13, 175-176.

Sutherland, N. S., \& Holgate, V. Two-cue discrimination learning in rats. Journal of Comparative and Physiological Psychology, 1966, 61, 198-207.

Telegdy, G. A., \& Cohen, J. S. Cue utilization and drive level in albino rats. Journal of Comparative and Physiological Psychology, 1971, 2, 248-253.

Tombaugh, T. The interactive effects of type of deprivation and sucrose concentration on acquisition and extinction performance in the rat. Canadian Journal of Psychology, 1974, 28, 351-358.

WINER, B. J. Statistical principles in experimental design (2nd ed.), New York: McGraw-Hill, 1971.

(Received for publication July 30, 1976.) 